\title{
The changing face of dental education
}

\begin{abstract}
A $s$ the team approach to dental practice has finally been formally acknowledged with the upcoming registration of the entire clinical team, the issue of dental education has taken on new meaning. In order to meet the inevitable increase in demand for training, teaching and learning, innovative approaches will be required and dental academia will be asked to respond. The educational needs can be viewed as a three dimensional problem, increased breadth across the dental team, vertical integration within and between specialties and the expansion longitudinally with lifelong learning and continuing professional development (CPD).
\end{abstract}

\section{Professionals complementary to dentistry}

Dental nurses, dental technicians, clinical dental technicians and orthodontic therapists will be required to register with the GDC from early 2005, joining dental hygienists and dental therapists on a PCD register. One of the incentives for registration will be that in return for proper recognition of their professional status there will be improved educational opportunities and a career progression structure allowing them to develop new skills and competencies. Inevitably there will need to be more resources put into training and CPD courses but details of the structures and funding are still to be resolved. In parallel with the above, professions complementary to dentistry need to be recognised for their contribution to the educational process. This coupled with pressure from the government and the public for greater accountability has encouraged the proposed introduction of a register for professionals complementary to dentistry. This opens up another avenue requiring the educational needs of these newly registered members of the dental team to be addressed.

\section{The dentist as the team leader}

Undergraduate and postgraduate education of dentists will require to be updated to keep pace with ongoing development within the profession. This is in line with public expectations and good educational practise, with an increasing emphasis on educational input and more formal outcome assessment in vocational training (VT) and general professional training (GPT). Increasing specialisation also re- quires new educational initiatives and continuing professional development is an ongoing requirement for all registered members of the dental team. The expanded dental team will include professionals complementary to dentistry and as a condition of registration and retention on the register there will be changes in how education for the PCDs is delivered. The dentist is being regarded as the team leader, and the educational process must be designed accordingly.

\section{Implications of The First Five Years}

In October 2002, the General Dental Council's Education Committee produced a comprehensive and innovative blueprint outlining the future shape of undergraduate dental education that has been generally well received. This document presented a significant challenge for the dental education establishment who are charged with ensuring that the objectives laid down by the GDC are implemented.

\section{Appropriate clinical experience}

Interaction and reciprocation between delivery of clinical services and delivery of dental education has been one of the enduring characteristics of the training of medical personnel in the UK. On graduation, dental professionals require to be competent surgeons in an increasingly specialised and complex environment outside of the dental school and this has led to the realisation that dental training should also include exposure to a range of clinical service delivery and patient care beyond the 'sheltered' environment of the dental school. The recognition of the need for trainees in dentistry to experience a range of clinical environments combined with geographical imbalance in the availability of NHS dentistry has led to the innovation known as 'outreach' teaching. With the improvement in computer literacy in IT facilities such as internet, digital imaging and electronic patient records, future education of strategies will incorporate computer assisted learning and problem based learning innovations. One of the major challenges that this presents, however, is ensuring the maintenance of high standards of clinical and educational excellence. Part of this will be the training of those who will assist with the provision of educational and clinical supervision outside the dental schools.
"In order to

meet the inevitable increase in demand for training, teaching and learning, innovative approaches will be required and dental academia will be asked to respond.' 


\section{Dental Outreach Schemes}

A basic educational principle in relation to clinical and professional competencies is that the optimum learning environment is the same environment as that in which the skill will be practised and in the context of dentistry, for the majority, this will be general dental practice rather than dental hospital practice. An ideal educational environment must also strive to confer state of the art skills and knowledge with exposure to a comprehensive range of operative techniques, equipment and materials. Undergraduate dental education through dental hospitals aims to provide this environment. Outreach schemes and dental hospitals therefore are not alternative educational environments, they are complementary and necessary to ensure comprehensive education. Dental hospitals represent economy of scale by enabling tuition and supervision in groups with an economic student to staff ratio. By virtue of this aim to provide simulated practice conditions, the outreach learning environment may require more intensive staff input and will require funding commensurate with this objective.

The objectives of an outreach scheme will vary from school to school and from one geographical region to another. In certain parts of the UK, there is also an element of social engineering involved. Remote areas and those where NHS dental service is not readily available are being targeted in the hope that students will have an opportunity to experience the social as well as the professional environment in what might be described as less attractive areas of the country. The success of such an experiment will depend on the attitude and expectations of new graduates who, in general terms, tend to favour a lifestyle and social environment only found in the larger conurbations throughout the country and perhaps to a limited extent by financial reward.

\section{Redefining dental academia}

In the last decade there have been very significant changes in the role and formal recognition of dental academics as teachers and educational facilitators. In the past experience and expertise in teaching was developed through clinically trained personnel with an academic interest themselves learning by 'on the job' experience. The universities now, however, expect academics in higher education to have formal qualifications, and through the Institution for Learning and Teaching in higher Education (ILTHE) dental academics throughout the UK seek formal certification of their educational expertise. Simultaneously, staff development initiatives have been implemented to improve expertise in the delivery of education to ensure maintenance of high standards of both clinical and educational excellence. There is also recognition of the need for educational research to optimise methodologies for teaching, learning and assessment that underpin contemporary educational practise. Meanwhile, within dental schools, academics will be expected to adapt to the changing environment and academic staff will need to learn new skills as directors of the educational process and become more involved in educational research in the foreseeable future.

\section{The new role of the dental schools}

While dental schools attached to universities throughout the UK will continue to be the focus of learning for the education and training of undergraduate dental students, it is acknowledged that dental schools alone will not provide the total learning environment for undergraduate or postgraduate dental training. A number of simultaneous challenges present that will have implications for the delivery of dental education, such as the need for evidence base for educational methodologies, improved methods of assessment, dental education in outreach and the role of professions complementary to dentistry.

Peter Mossey, BDJ Adviser on Dental Education
'While dental schools will continue to be the focus for the education and training of undergraduate dental students, it is acknowledged that dental schools alone will not provide the total learning environment for undergraduate or postgraduate dental training." 